\title{
Scaling up the Fabrication of Mechanically-Robust Carbon Nanofiber Foams
}

\author{
William Curtin ${ }^{1}$, Pedro J. Arias-Monje ${ }^{2}$, Charliean Dominguez ${ }^{1}$, Jonathan Phillips ${ }^{3}$ and \\ Claudia C. Luhrs ${ }^{1, *}$ \\ 1 Mechanical and Aerospace Engineering Department, Naval Postgraduate School, Monterey, CA 93943, USA; \\ wcurtin@nps.edu (W.C.); cndoming@nps.edu (C.D.) \\ 2 Departamento de Ingeniería Química y Ambiental, Universidad Nacional de Colombia, Bogotá 111321, \\ Colombia; pjariasm@unal.edu.co \\ 3 Energy Academic Group, Naval Postgraduate School, Monterey, CA 93943, USA; jphillip@nps.edu \\ * Correspondence: ccluhrs@nps.edu; Tel.: +1-831-656-2568
}

Academic Editor: Ton Peijs

Received: 2 November 2015; Accepted: 31 January 2016; Published: 15 February 2016

\begin{abstract}
This work aimed to identify and address the main challenges associated with fabricating large samples of carbon foams composed of interwoven networks of carbon nanofibers. Solutions to two difficulties related with the process of fabricating carbon foams, maximum foam size and catalyst cost, were developed. First, a simple physical method was invented to scale-up the constrained formation of fibrous nanostructures process (CoFFiN) to fabricate relatively large foams. Specifically, a gas deflector system capable of maintaining conditions supportive of carbon nanofiber foam growth throughout a relatively large mold was developed. ANSYS CFX models were used to simulate the gas flow paths with and without deflectors; the data generated proved to be a very useful tool for the deflector design. Second, a simple method for selectively leaching the Pd catalyst material trapped in the foam during growth was successfully tested. Multiple techniques, including scanning electron microscopy, surface area measurements, and mechanical testing, were employed to characterize the foams generated in this study. All results confirmed that the larger foam samples preserve the basic characteristics: their interwoven nanofiber microstructure forms a low-density tridimensional solid with viscoelastic behavior. Fiber growth mechanisms are also discussed. Larger samples of mechanically-robust carbon nanofiber foams will enable the use of these materials as strain sensors, shock absorbers, selective absorbents for environmental remediation and electrodes for energy storage devices, among other applications.
\end{abstract}

Keywords: carbon nanofibers; carbon foam

\section{Introduction}

Testing and developing applications of novel carbon-based materials, including carbon nanotubes, nanofibers, and graphene, is limited by the difficulty of synthesizing sufficient quantities of high-quality, low-cost material. Indeed, there is a great deal of research devoted to improving synthesis of both nanotubes [1-5] and graphene [6-9]. The only mechanically-robust carbon fiber foams that exist at large scale are actually composites, containing both carbon fiber and polymeric materials [10-13]. Uniquely, the constrained formation of fiber nanostructures (CoFFiN) [14,15] provides a means to generate pure carbon fiber foams with mechanical and thermal stability. However, in prior work the fabrication of large samples was limited to small-sized molds. As demonstrated in the present work this limitation was a natural consequence of the complexity of growing large scale carbon fiber foams. Hence, the success of the scale-up process outlined in the present paper, and the concomitant development of 
a better understanding of the growth mechanism, are important steps in the development cycle of carbon nanofiber foams (CNFF).

Carbon nanofiber foams grown using the CoFFiN process, including those produced herein, are unique in that they consist of macroscopic mats of interwoven nano-scale carbon fibers. Using the CoFFiN process they are grown catalytically (e.g., $\mathrm{Ni}, \mathrm{Pd}$, or $\mathrm{Pt}$ particles) from fuel-rich mixtures of ethylene and oxygen over a limited moderate temperature range $\left(\sim 500\right.$ to $\left.700{ }^{\circ} \mathrm{C}\right)$. The foam possesses unique properties that would be advantageous to exploit. For example, they share the properties of other macroscale objects composed of nanoscale carbon, such as electrical conductivity [16,17] and thermal stability up to at least 500 degrees in air atmosphere [14]. Applications under study for such materials include shock absorbing for use in personal protection systems, oil absorbents for environmental remediation, lightweight structural composites, catalyst supports, thermal management, and electrodes for energy storage systems, among others [18-25]. One potential application is the use of CNFF, as the sensing element in strain gauges, has already been demonstrated [14].

The difficulty of growing large CNFF is linked to the fundamental chemistry of the process. As demonstrated in the many studies of carbon growth from fuel-rich hydrocarbon mixtures, the so-called Graphitic Structures by Design (GSD) technology, carbon grows catalytically from radical species formed by homogeneous combustion [26-29]. To understand this mechanism it is useful to contrast GSD with fiber growth in oxygen-free environments. Specifically, in oxygen-free environments, carbon fibers and/or nanotubes grow via the catalytic decomposition of organic molecules. First, the molecule adsorbs on a metal particle catalyst surface; second, the molecule decomposes; and third, there is transport of carbon atoms driven by chemical potential gradients to a growing carbon filament/catalyst particle interface [30-33]. In contrast, the process occurring in oxygen-containing, fuel-rich, combustion environments is closer, chemically, to the production of soot. It is well known that soot growth occurs via reactions between a growing soot nucleus and radical species formed via homogeneous combustion. Hence, soot growth [34] and fiber growth via the GSD process only take place in that part of a "flame" in which the appropriate radicals are present. The conditions in which particular radical species are present is a function of temperature, generally far lower than that required for growth in oxygen-free environments, and residence time. Hence, the "spatial range" over which proper conditions for carbon growth in a combustion environment is limited. In brief, the catalyst particles are only effective if they are placed in that region of the fuel rich combustion zone in which the proper radicals for carbon growth are present. In other words, the flow rates and temperatures must be adjusted such that the catalyst encounters the combusting gas flow over the brief "residence time" compatible with particular radicals being present in high concentration.

There are many control parameters that can influence the growth process, and the quality of the product, during the production of carbon fiber foams in a mold. As elucidated in earlier papers, they include gas flow rate, pre-heat time, temperature, catalyst position, catalyst density in the mold, temperature program, and process time $[28,29,35,36]$.

In the present work a growth mold 20 times larger, by volume, than any previously employed was successfully used to make a high-quality, single CNFF. Given that the growth chamber could not be modified to have a top-down circular geometry for gas entry and that the available furnace consisted of a rectangular volume with interior dimensions of $13.7 \mathrm{~cm} \times 18.75 \mathrm{~cm} \times 35 \mathrm{~cm}$ and a single front gas entry port, this was not a simple process. Indeed, it was quickly found that growth of a quality single piece of fiber foam was not possible simply by injecting the gas mixture into the mold. To ensure proper growth two modifications were required. First, the length of the tube that conducted the reactive gases into the furnace containing the reactor was adjusted. Second, a gas deflector system was designed to create flows within the reactor such that every catalyst particle encountered the gas at approximately the same "residence time". Finally, a leaching method was employed to recover the costly palladium used as the catalyst in the system. It was found that this recovery process did not materially alter the properties of the CNFF. The process for designing this system consisted of both trial and error and analysis of the impact of the deflector on flows using the ANSYS CNFF program. 
Finally, it should be noted that all characterization studies: SEM, density measurements, and mechanical testing indicated these foams were virtually identical to the smaller CNFF described in earlier work, and far more mechanically robust than commercially available cellular carbon foams.

\section{Experimental Section}

\subsection{Carbon Nanofiber Foam Growth}

The process to grow the fiber foam consisted of four main steps: (1) spread by hand $0.5 \mathrm{~g}$ of palladium powder catalyst (Sigma Aldrich, Milwaukee, WI, USA; $<1 \mu \mathrm{m}, 99.9 \%$ ) within the main chamber in a diagonal pattern (in some cases add gas deflectors) and seal the chamber with a lid, adapt the gas connections, and place inside a muffle furnace (Thermo Scientific, Waltham, MA, USA; LindBerg Blue M); (2) flow nitrogen gas (Praxair, CA, USA. Ultra high purity, $300 \mathrm{sccm}$ ) to remove air from chamber and gas lines; (3) raise the temperature to $550{ }^{\circ} \mathrm{C}$ and introduce reactive gases $\left(\mathrm{N}_{2}, 300 \mathrm{sccm} ; \mathrm{O}_{2} 45 \mathrm{sccm} ; \mathrm{C}_{2} \mathrm{H}_{4}, 45 \mathrm{sccm}\right)$; and (4) allow reaction to take place for $10 \mathrm{~h}$. These steps were followed by a cool down in $\mathrm{N}_{2}$ atmosphere $(300 \mathrm{sccm})$. An ethylene trap, followed by a water trap, were attached to the system exhaust.

\subsection{Mold-Lid Construction and Deflector Material}

A $15 \mathrm{~cm} \times 15 \mathrm{~cm} \times 5 \mathrm{~cm}$ block of stainless steel was milled into the finalized design (Figure 1) using a Hass VF-6 CNC mill capable of five-axis rotation due to the use of its TRT-310 trunnion table. The CNC machine was used to create all threaded connections, the gas flow inlets and outlets, the inlet and outlet chambers, and the larger main chamber. The gas flow tunnels that connect the chambers were created using a drill press. These chambers and tunnels are identified in Figure 1. The external access holes (which were required to create the chambers and tunnels) were completely sealed by plugging the hole with 308 stainless steel welding filler material. The inner final volume of the mold measured $11.25 \mathrm{~cm} \times 12.5 \mathrm{~cm} \times 1.9 \mathrm{~cm}$.

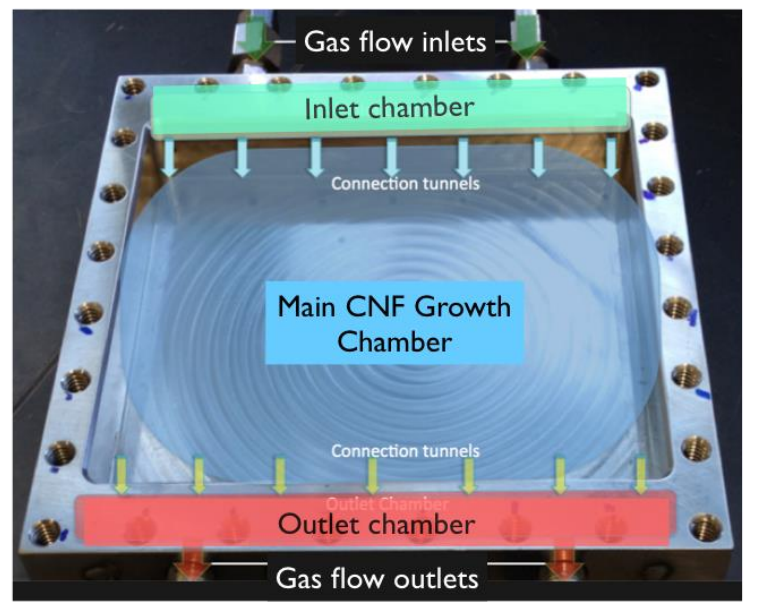

Figure 1. The mold design included inlet and outlet connections, rectangular inlet and outlet chambers (where gases spread out), and connection tunnels from those to the main growth chamber. The mold had a lid that hermetically sealed the growth chamber.

The deflectors to direct the reactive gases to different locations of the chamber were made of stainless steel shim (Trinity Brand Industries, Inc., Countryside, IL, USA; Part No. 6316-4). The evolution of the deflector system is shown in Figure 2. Initially, the deflector only comprised a bottom section that held the particles, along front and side flaps, placed in front the gas inlet connection tunnels, forcing the gas to distribute from the inlet in top and down grooves and in the sides towards the back section of the mold (Figure 2a). Since observations showed minimal growth in areas in the 
middle and back of the growth chamber, subsequent designs included a top deflector that directed gas to those areas (Figure 2b-f). The final design that successfully produced a single mechanically-robust tridimensional foam is shown in Figure $2 f$ and includes a deflector that directs the gas inside the chamber toward the upper section of the outlet. A final aspect of the reactor design was the use of a serpentine gas inlet tube coil to increase the residence time of the reaction mixture, at furnace temperature, before it reached the main chamber. This was done, as explained below, in accordance with the radical-based model of fiber growth (Figure 3).
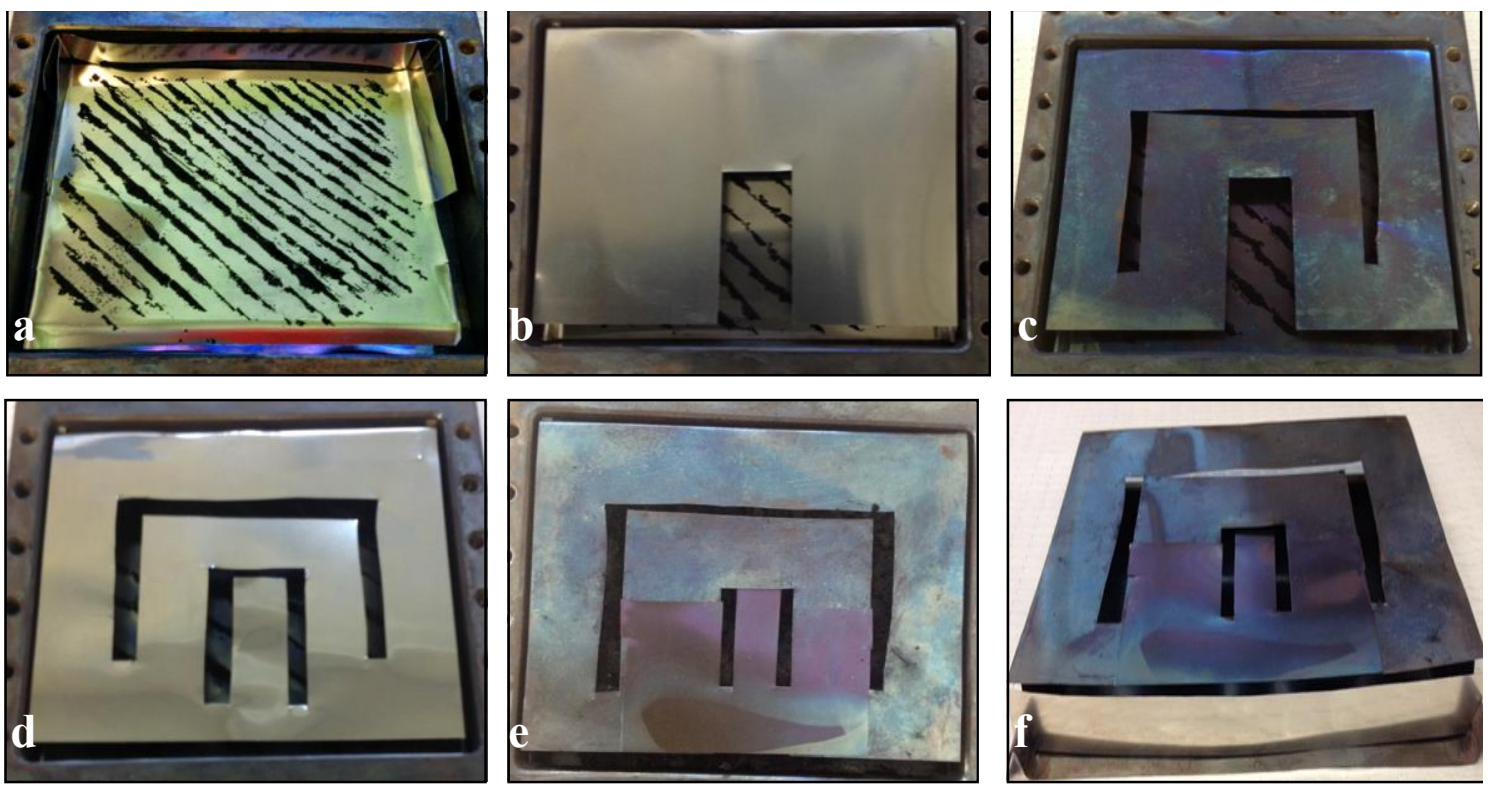

Figure 2. Evolution of the deflector design. Deflector design progression (a-f) was based on the experimental results and ANSYS models of gas distribution predictions.

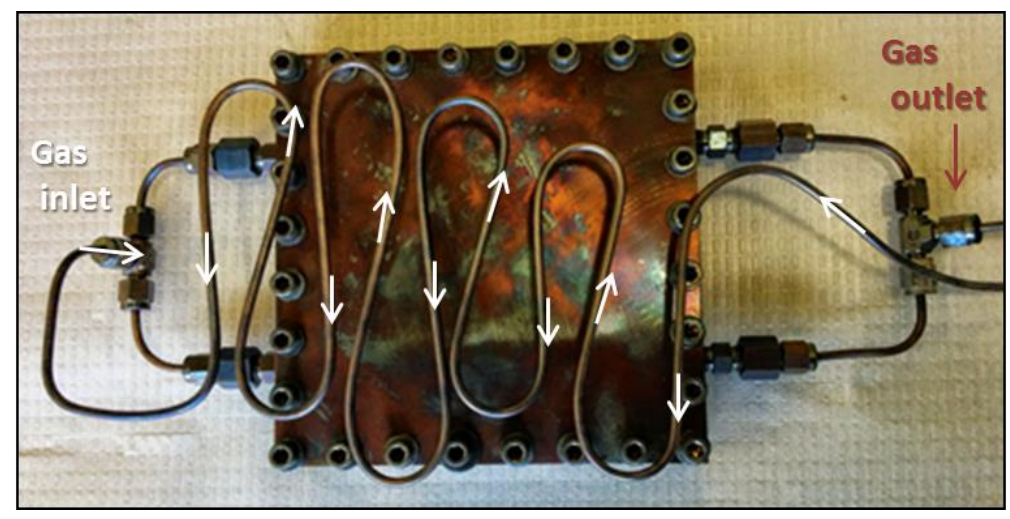

Figure 3. Serpentine used to increase gas residence time inside furnace and, thus, temperature.

\subsection{ANSYS Modeling}

The commercial fluid flow modeling engineering software ANSYS [37] was used to predict how diverse deflector configurations will distribute the reactive gases inside the growth chamber. It is worth noting that the models do not account for the gas path changes suffered as a consequence of the fiber foam growth. 


\subsection{Palladium Catalyst Recovery}

The Pd catalyst used for the fiber growth was based on the work of Sarioglan et al. [38]. The process extracts palladium (spent catalyst) from carbon-based mixtures by the use of solutions containing dilute hydrochloric acid, $\mathrm{HCl}$ (Sigma-Aldrich ACS reagent) and hydrogen peroxide, $\mathrm{H}_{2} \mathrm{O}_{2}$ (Sigma Aldrich $30 \%$ solution). Diverse concentrations (10\% hydrochloric acid by itself and mixed with a $5 \%$ hydrogen peroxide solution) and times (from $0,15,30,60,90$, and $120 \mathrm{~min}$ to up to $18 \mathrm{~h}$ ) were tested with a reaction temperature of $60^{\circ} \mathrm{C}$. The resulting carbon foam was then washed with DI water, ethanol and dried under inert atmosphere. The acid treated CNFF products were analyzed by SEM-BSE to evaluate the effectiveness of the process to remove the catalyst. The backscattered electron (BSE) images are formed by high-energy electrons (that originate at the electron beam) that are elastically scattered by the sample interaction volume. Heavy elements (high atomic number) backscatter electrons more strongly than lighter elements (low atomic number) and appear brighter in the BSE image, thus, showing contrast between areas in the specimen with different composition.

\subsection{Characterization Techniques}

A Zeiss Neon 40 High-Resolution Scanning Electron Microscope (SEM, Zeiss, Oberkotchen, Germany) was employed to acquire secondary electron (SE) and backscattered electron (BSE) images of the fiber foam products at diverse magnifications while microscope was operated at 10 or $20 \mathrm{kV}$.

Mechanical testing was performed as described in earlier studies [14] using an INSTRON 5942 with a $100 \mathrm{~N}$ load cell, configured to study the material in compression. The compressive force was selected to remain between 10 and 90 Newton. The lower limit was selected in order to prevent the carbon nanofiber from losing contact with the anvil while the upper limit was chosen to prevent reaching the $100 \mathrm{~N}$ automatic cutout limit on the load cell used in the test.

The relative density of the foam produced herein was calculated from the mass of a section of the material and the volume of DI water it displaced. The surface area values of the samples were calculated by the Brunauer Emmet Teller (BET) method using nitrogen as the absorbate. The analysis was performed in a Quantachrome Nova 4200 (Quantachrome Instruments, Boynton Beach, FL, USA).

\section{Results and Discussion}

The development of a process for growing relatively large scale CNFF is best understood in terms of three phases of development. In the first phase (Section 3.1), it was clearly demonstrated that a simple strategy would not produce a mold-filling, high-quality fiber foam. Specifically, it was experimentally shown that running a fuel-rich ethylene/oxygen mixture through multiple inlets into a mold in which Pd catalyst particles were evenly distributed, produced only a small quantity of quality fiber foam near the gas inlets. This first phase assumed that the growth mechanism of the fibers occurred in the same fashion that typical CVD-root growth processes are explained: catalyst particles exposed to hydrocarbons at high temperatures will produce a mat of fibers.

In the second phase (Section 3.2), ANSYS models of flow patterns in molds, both with and without gas deflectors, were analyzed. This work clearly showed that deflectors could be designed that permitted gas to encounter catalyst particles at roughly the same residence time $[39,40]$ throughout the rectangular mold. This second phase is consistent with a growth model in which the formation of radical species at a certain time and location are necessary for fiber formation.

Finally, in the third phase a number of deflector designs consistent with the radical growth-GSD model (Section 3.3) were tested experimentally. Using the sixth iteration on deflector design a mold-filling, high-quality, fiber foam was produced.

\subsection{Growth Experiments}

In this first phase a very simple growth scheme was applied. This design was based on the assumption that the mechanism of carbon growth is a type of chemical vapor deposition (CVD), a 
mechanism associated with many forms of carbon growth from vapor phase hydrocarbons at elevated temperature [26,30-33,41,42]. The CVD model assumes that carbon structures, including filaments, will grow on proper metal catalysts, particles, foils, etc., above the experimentally-determined breakdown temperature, generally between 500 and $1200{ }^{\circ} \mathrm{C}$, of the organic precursor molecule, and that the process will continue until the hydrocarbon is fully depleted. Thus, in the first phase of this work, Pd catalyst particles, demonstrated to be excellent fiber foam catalysts earlier [35,43],were spread evenly over the floor of the mold and the gas mixture introduced at one end of the mold and exited at the other. Clearly, in this arrangement, all of the catalyst particles will encounter unburned hydrocarbons as there is not sufficient oxygen in a fuel rich mixture to burn all the hydrocarbon. Indeed, given the experimental 1:1 oxygen:ethylene ratio, and the fact that full combustion requires a 3:1 ratio, it is clear that, at most, $33 \%$ of the ethylene is combusted. (In contrast, the oxygen could be depleted by reaction far earlier.) Hence, filament growth can be expected, according to the CVD model, across the entire chamber.

As shown in Figure 4, the CVD model clearly does not explain the outcome. Fiber growth is irregular, and only found in part of the chamber. The inlet region foam has deep grooves that line up with the gas inlets. A single piece of quality foam formed in the forward third of the chamber, but the quality of the foams deteriorated past this point. The foam was found in smaller and smaller disconnected "bits", and was actually composed of very thin $(<0.5 \mathrm{~mm})$, individual, foam flakes after the chamber mid-point. The catalyst particles in the rear third of the chamber did not grow any fibers or foam, except along the chamber walls. Although there is clearly unburned hydrocarbon across the entire chamber, no growth is found to occur at all in the back of the chamber, even after $10 \mathrm{~h}$.

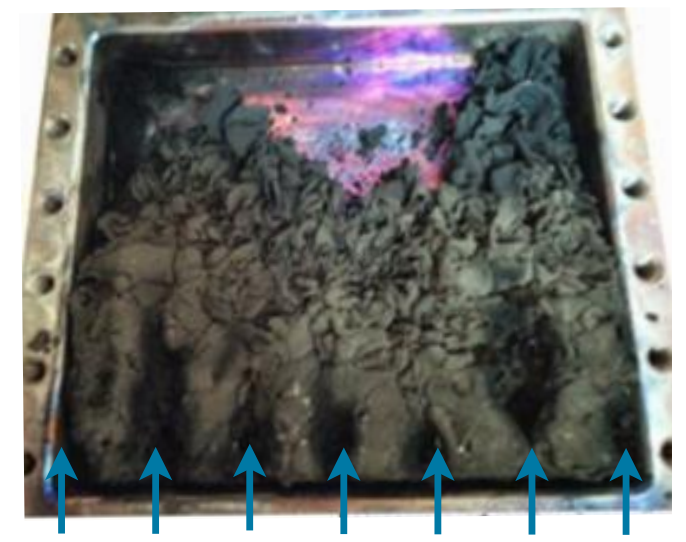

Figure 4. Carbon nanofiber growth inside a mold. The arrows represent the inlet channels where reactive gases entered the chamber but hinder the fiber growth.

\subsection{ANSYS Flow Models}

ANSYS flow models were developed to show how the use of deflectors will provide a more even distribution of gases. In the absence of deflectors (Figure 5) the flow lines tend to cancel each other and produce simple lines that leave areas of the growth chamber untouched. In practice, in the absence of any deflectors, growth of real fiber foam is only found in the front third of the chamber, in "lines", as described in previous section.

The inclusion of deflectors (Figure 6) in the model demonstrates that the flows get simultaneously distributed to the top, sides, rear and back of the growth chamber. Indeed, in the case of the most successful deflector (Figure 2f), as determined experimentally, gas reaches the back-front-middle sections of the reactor at nearly the same residence time. Thus, the chemical species present in the homogeneous phase, due to partial combustion, are nearly the same in each section of the reactor. 
As time progresses, clearly the ANSYS flow models are no longer completely valid. Carbon fiber foam grows in the inlet area, and this will modify the flow field. No attempt was made to model this situation.
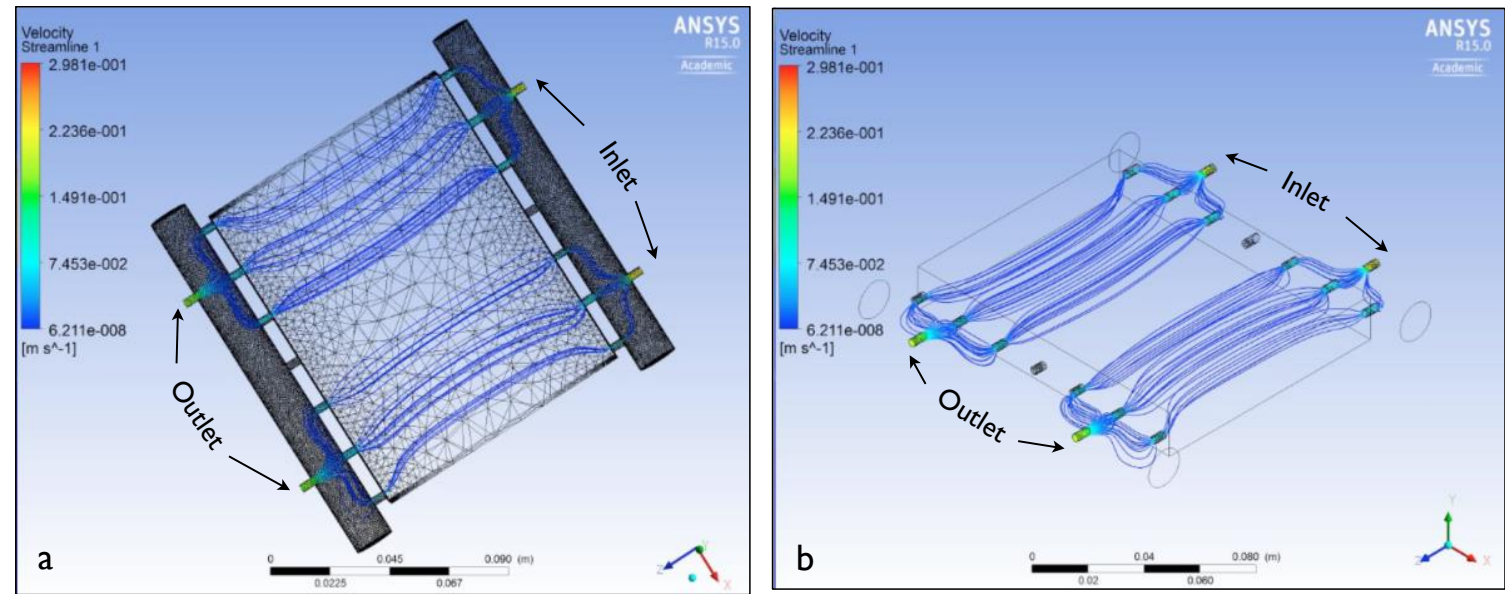

Figure 5. ANSYS model that simulates gas flows in a growth chamber with no deflectors. (a) Top view and (b) lateral view.
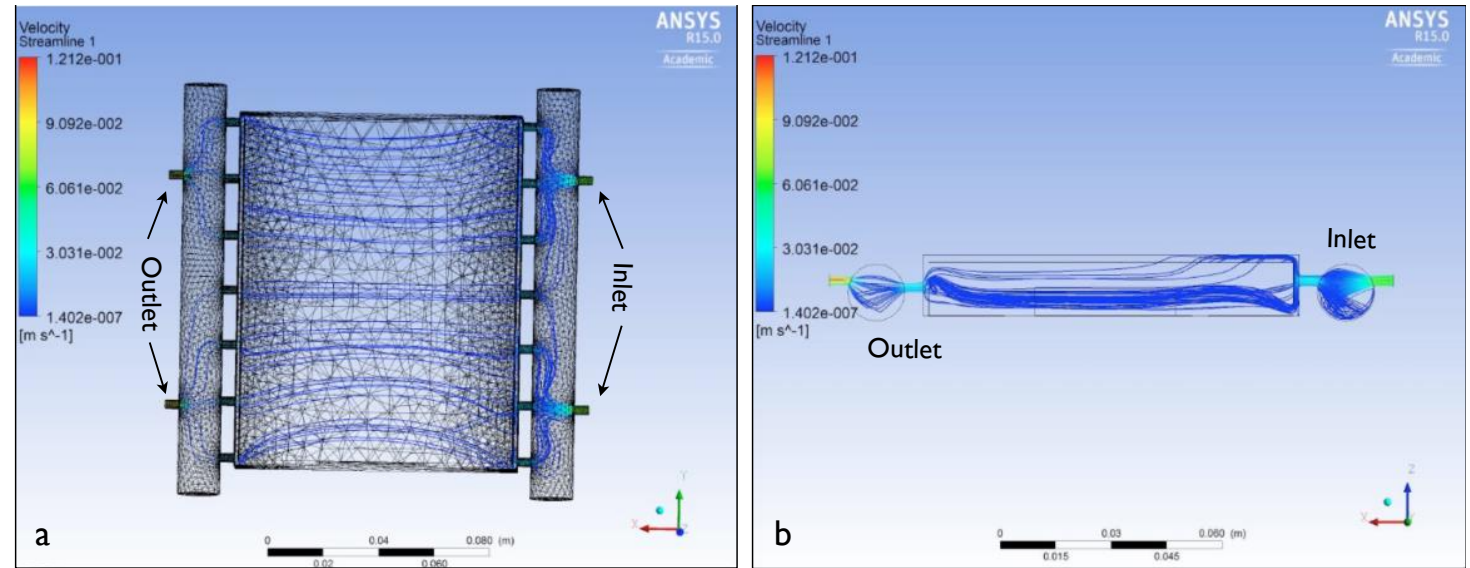

Figure 6. ANSYS model that simulates initial gas flows inside the growth chamber when the geometry of deflector shown in Figure $2 \mathrm{f}$ is included. (a) Top view and (b) side view.

According to the GSD model the identity of the radical species determines the growth rate. The particular radicals responsible for growth will only exist over a relatively short period of time. Thus, it is key to have all catalysts placed such that they are at equivalent residence time positions within the reactor to promote rapid, simultaneous filament growth in all regions of the mold. The sections presented below discuss how the inclusion of deflectors support the growth model based on radical species.

It must be made clear that the gas flow model cannot reveal all aspects of a chemical process. It does not show the residence time of gas at any point in the mold. It also does not show the impact of the reaction on the oxygen concentration, required to create radicals, at any point in the mold. It does suggest that a deflector can be used to get gas to flow rapidly by convection to all parts of the mold. In the absence of a deflector, gas reaches large parts of the mold by diffusion (relatively slow) rather than convection. ANSYS flow models can only be a guide for experimental trials, that are required to determine optimal conditions for fiber foam growth. 


\subsection{Growth Model Based on Radical Species (GSD)}

Based on the results of the first experiment, and the demonstration by ANSYS that a deflector can significantly modify the flow pattern, and in fact create convection to all parts of the mold, a trial and error deflector design program was undertaken. The trial and error approach, rather than modeling, was employed because of the impossibility of providing all relevant parameters (such as initial reaction rates, impact of heterogeneous sites on reaction rate, the geometry of the foam as a function of time, etc.) by the ANSYS or any other simulation approach.

A total of six deflectors were designed and tested. In all cases most of the operating parameters including gas flow rates, amount of catalyst, and furnace temperature were kept at the same value. In the final three trials the amount of time allowed for foam growth was doubled.

Only the last deflector design (Figure 2f) produced a single, high-quality fiber foam. All of the others (Figure 2a-e) produced bits of disconnected fiber foam, did not permit the foam to fill the entire chamber, or produced foams of uneven quality. Only the structure of the final two deflectors (from Figure 2e,f) and detailed descriptions of the foams produced are provided in detail below. Some features of the foams produced with all the designs are provided in Table 1.

Table 1. Percent of chamber filled by foam by deflector design (numbers correspond to figure numbers in experimental section).

\begin{tabular}{|c|c|c|c|c|c|}
\hline \multirow{2}{*}{ Deflector } & \multirow{2}{*}{$\begin{array}{c}\text { Catalyst (Pd) } \\
\text { weight }(g)\end{array}$} & \multicolumn{3}{|c|}{ Gas flow (sccm) } & \multirow{2}{*}{$\begin{array}{l}\text { Percent of chamber } \\
\text { filled (\%) }\end{array}$} \\
\hline & & $\mathbf{N}_{2}$ & $\mathrm{O}_{2}$ & $\mathrm{C}_{2} \mathrm{H}_{4}$ & \\
\hline $\mathrm{N} / \mathrm{A}$ & 0.680 & 100 & 15 & 15 & 33 \\
\hline $2 a$ & 0.500 & 300 & 45 & 45 & 55 \\
\hline $2 b$ & 0.510 & 300 & 45 & 45 & 60 \\
\hline $2 c$ & 0.508 & 300 & 45 & 45 & 75 \\
\hline $2 d$ & 0.501 & 300 & 45 & 45 & 60 \\
\hline $2 \mathrm{e}$ & 0.503 & 300 & 45 & 45 & 85 \\
\hline $2 \mathrm{f}$ & 0.506 & 300 & 45 & 45 & 100 \\
\hline
\end{tabular}

Deflector 2e-The outcome is nearly acceptable (Figure 7a). It is clearly seen that over a large fraction of the mold a single piece of constant-quality foam is found. However; it is also clear that near the center of the mold there are "seams" in the foam. These seams did not correlate with breakage. The fiber foam held together firmly as a single entity.
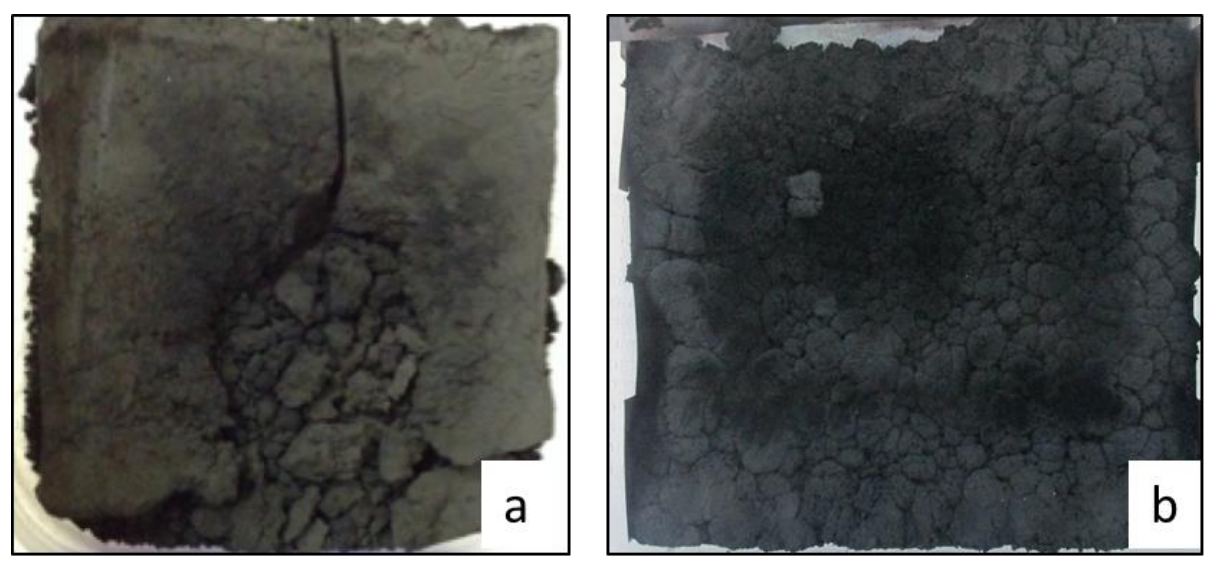

Figure 7. Comparison between product generated by the use of deflectors in Figure 2e (a) and Figure $2 \mathrm{f}(\mathbf{b})$.

Deflector $2 \mathrm{f}-$ The foam generated with the final deflector studied is shown in Figure $7 \mathrm{~b}$. The deflector, itself, is different from deflector $2 \mathrm{e}$ only because of the removal of the steel section in the top 
of the deflector and repositioning of the groove in the top to allow gases to exit. The gas was forced to travel "up and around" in order to reach the outlet lines. Yet, the addition of the rear deflector significantly improved the outcome. It permitted good quality textured CNFF to form in all regions (Figure $7 \mathrm{~b}$ ), including the center rear region of the main chamber. This allowed for the removal of the block as a single unit (Figure 8). Despite the appearance of minor CNFF nucleation clusters that formed atop the interwoven mat below, the experiment was determined to have met the objectives of developing a mechanism for creating "large" CNFF.

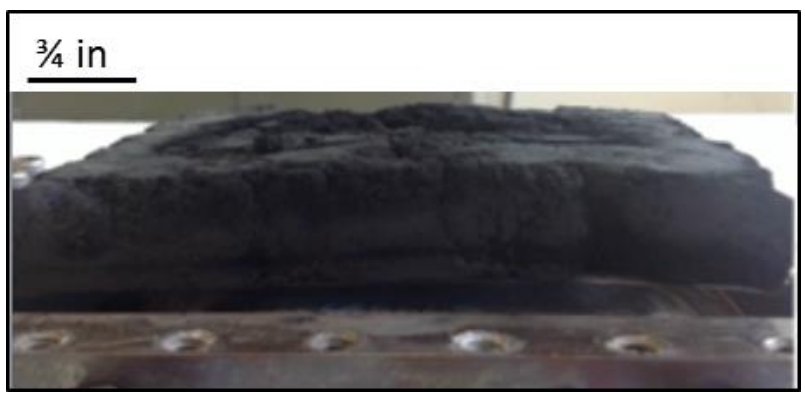

Figure 8. Tridimensional foam generated by the deflector shown in Figure 2f.

SEM images taken from a sample of the CNFF show the size characteristics of the CNFF fibers closely match those obtained from the preliminary experiments (Figure 9). This is important because it indicates that, despite the increased scale of the generated foam, the foam fibers produced continue to have the same desired physical characteristics as those produced in the earlier preliminary experiments [14].
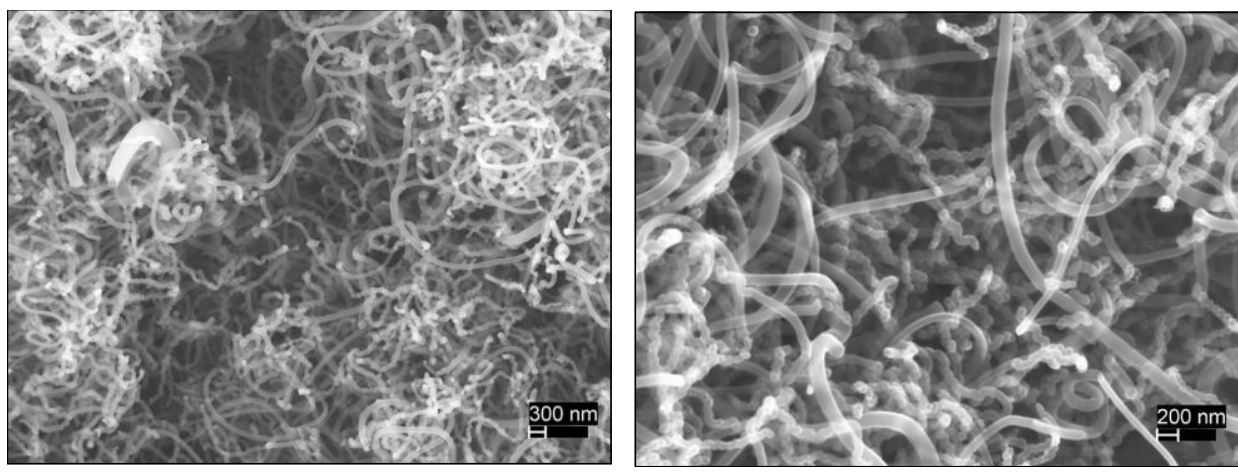

Figure 9. SEM micrograph of the foam structure at two magnifications (see scale bars). The foam consists of interwoven carbon nanofibers with diameters between 20 and $200 \mathrm{~nm}$.

Another important indicator of the success of the "scale up" is the consistency of the physical properties of the foam produced in the present work (Figure 10) with that of foam samples produced earlier on foams made using the CoFFiN process in a mold only $5 \%$ the volume of that employed in the present study [14]. The density of the product was $0.3 \mathrm{~g} / \mathrm{cm}^{3}$, slightly larger than previously reported but still just above the density of cork [44]. The surface area of the foam as prepared was $59 \mathrm{~m}^{2} / \mathrm{g}$ and $89 \mathrm{~m}^{2} / \mathrm{g}$ after the Pd removal process.

The mechanical behavior of the foams generated show nearly identical characteristics to that observed in earlier work: when subject to cyclic loads, the stress versus strain curves present a hysteresis loop characteristic of viscoelastic materials, exhibiting a time delay in returning to the original shape. Figure 10a shows a comparison for cyclic loads conducted for the carbon nanofiber foam produced at diverse rates showing that the foam becomes stiffer as the load rate increase. The CNFF foam 
showed no mechanical degradation even after dozens of full cycles. This outcome is consistent with the suggestion that CNFF produced using CoFFiN are mechanically-robust pure carbon foams.

The growth behavior observed experimentally in the presence of deflectors is consistent with the radical species-GSD model: filament growth requires the right radicals to be produced in the vicinity of the catalyst particles. That is, true precursors to carbon growth are homogenously-formed radicals that are generated by combustion processes $[26,29,45]$. As demonstrated in earlier publications $[35,46]$, the rate of carbon growth is a strong function of the placement of the catalysts relative to the residence time of the reactant mixture. The best growth radicals, according to this model, are only present over a small interval of residence time. Hence, the physical position of catalyst particles relative to gas velocity, vessel volume, material with active surface area, etc. will determine if growth occurs on the catalysts.

Virtually identical mechanical testing was also performed on two cellular carbon foams available commercially. These foams completely disintegrated one third of the way through the first leg of the compression process. The CNFF foam, in contrast, showed no mechanical degradation even after dozens of full cycles. This outcome is consistent with the suggestion that CNFF produced using CoFFiN are the only mechanically robust pure carbon foams.

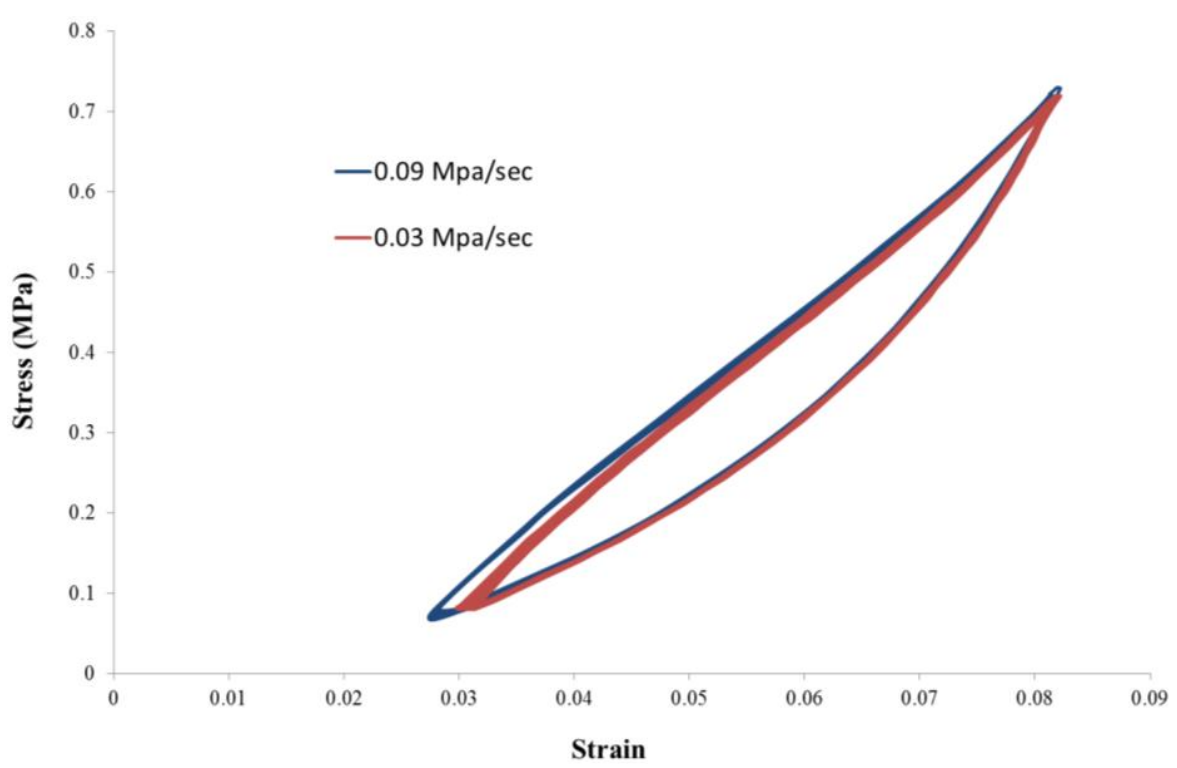

Figure 10. Mechanical testing. Mechanical tests demonstrate that the foam (Deflector $f$ ) made in the present study is viscoelastic, and behaves in a virtually identical manner to that of a far smaller foam made using the same recipe.

It is important to note that the gas flow rates employed in this work, and the length of the serpentine entry coil, were coordinated such that at the entry point to the reactor, the reacting mix would have reached that residence time at which high growth was observed in earlier work. Thus, the high rate of filament growth observed in the entry area of the reactor, and the absence of growth at the back, is anticipated by the radicals model. The residence time at the back of the reactor is too long for proper radical formation.

The use of diverse mixtures of $\mathrm{HCl}$ and $\mathrm{H}_{2} \mathrm{O}_{2}$ were tested to dissolve the Pd catalyst. The dried carbon foam product that resulted from the acid treatment described in the experimental methods was studied by SEM (backscattered electron mode, BSE) to evaluate the conditions (time, temperatures and concentrations) that were more effective for Pd removal. On Figure 11a-c, the brighter regions correspond to Pd sites, while the carbon sections of the foam are shown as darker tones of grey. The SEM-BSE images were then processed with the software ImageJ [47], which allowed the quantification of the fraction of the area occupied by the brighter regions (Figure 11d-f) and the grey regions where 
the carbon foam was located (not shown), thus providing a means to roughly compare among samples treated for different times. The empty regions (black) were subtracted in all cases. It is evident, both from the BSE images and from the quantification performed by ImageJ, that the amount of Pd particles diminishes as the acid treatment time increases. Indeed, the samples treated at 0,90 , and $120 \mathrm{~min}$ had a Pd:C ratio of 1:64, 1:110, and 1:822 respectively. SEM images acquired at higher magnifications did not show indication of fiber surface degradation as result of the treatment. In sum, the conditions used to dissolve palladium, proved to be effective and could be used to recover the metal and reduce production costs in future operations.
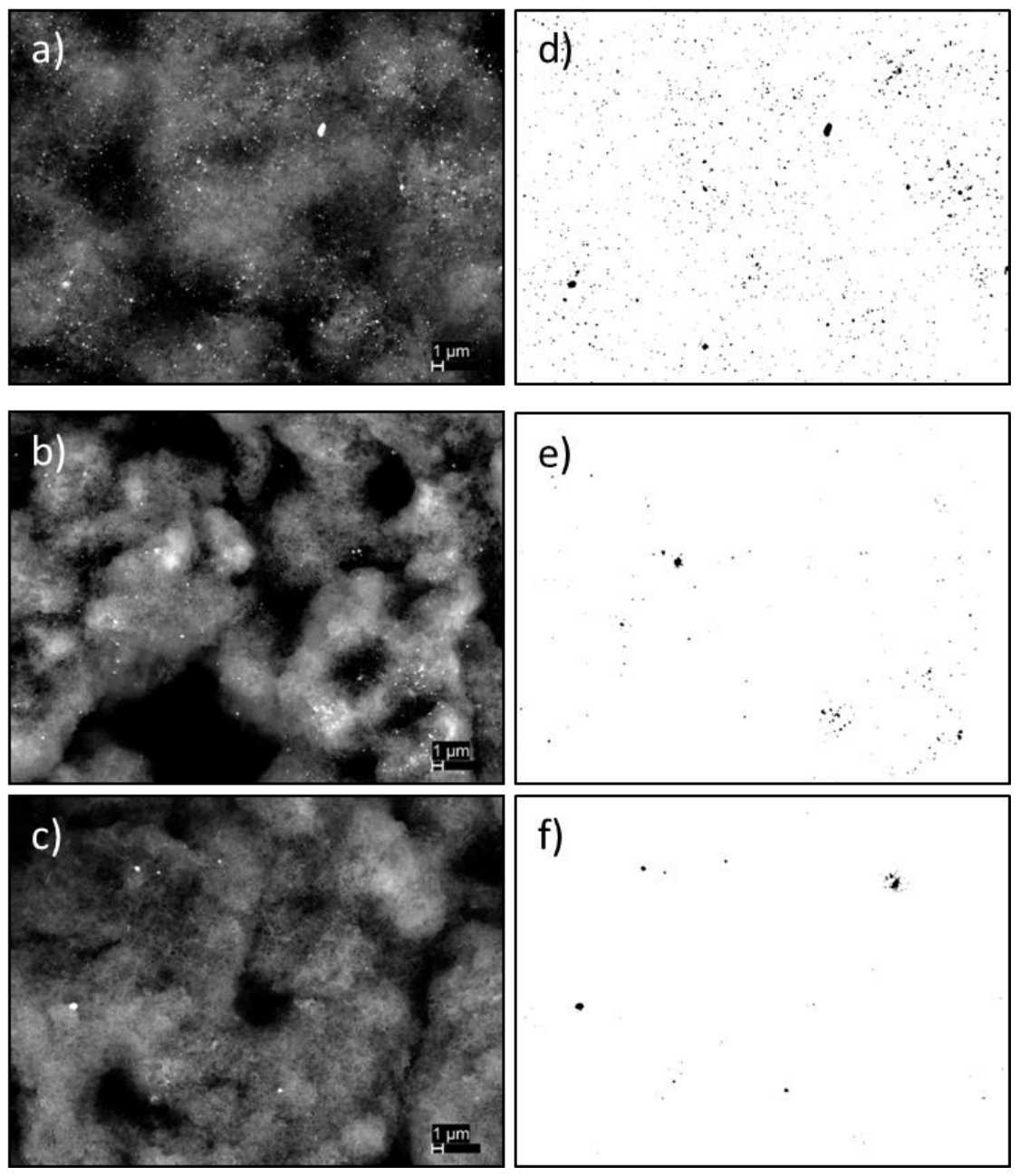

Figure 11. Left: SEM-BSE images of samples treated in an aqueous solution composed of $10 \%$ hydrochloric acid and 5\% hydrogen peroxide held at $60^{\circ} \mathrm{C}$ for (a) 0; (b) 90, and (c) 120 min. Right: $\mathrm{Pd}$ regions identified by software ImageJ for samples treated for (d) 0; (e) 90, and (f) $120 \mathrm{~min}$.

\section{Conclusions}

This work demonstrated that large fiber foam structures can be generated using the CoFFiN process; however, it required a careful design of the reactor such that the fuel-rich gas mixture reached all areas of the mold at approximately the same residence time. Specifically, using the CoFFiN process at $550{ }^{\circ} \mathrm{C}$, employing Pd particle catalysts, and a 1:1:6.7 $\mathrm{C}_{2} \mathrm{H}_{4}: \mathrm{O}_{2}: \mathrm{N}_{2}$ gas mixture, a homogenous, physically-continuous, high-quality, mold-filling carbon fiber foam of approximate dimensions $11.25 \mathrm{~cm} \times 12.5 \mathrm{~cm} \times 1.9 \mathrm{~cm}$ was generated. Notably, to form this large foam required the use of a deflector able to distribute the gas evenly. Although an ANSYS flow model was employed to assist in the design of the deflector, the final design was empirical. Six different deflector designs were 
tested, and only one led to the generation of a mechanically-robust, single 3D piece foam. The control study, simply running the gas mixture from one end of the mold to the other, only generated high quality foam in the first third of the mold volume. These results are consistent with the radical/GSD model of carbon fiber growth: fibers form due to the decomposition of radical species that form homogenously during combustion. To reduce the cost of the process, the palladium catalyst was recovered by dissolving it in a mixture of $\mathrm{HCl}$ and $\mathrm{H}_{2} \mathrm{O}_{2}$ at $60^{\circ} \mathrm{C}$, and the treatment did not degrade the quality of the carbon foam. In sum, this work successfully addressed the two main challenges associated with fabricating large samples of carbon foams composed of interwoven networks of carbon nanofibers: it increased the maximum foam size and proposed a route to reduce the catalyst cost.

Acknowledgments: This work was supported by the Office of Naval Research, Code 30, Force Protection Thrust.

Author Contributions: Claudia C. Luhrs and Jonathan Phillips advised the work, devised experimental conditions, analyzed data and wrote the manuscript. William Curtin generated the ANSYS models, conducted most experiments regarding fiber foam growth and performed some of the samples characterization. Pedro J. Arias-Monje collaborated in the foam growth, Pd removal experiments and characterization by SEM. Charliean Dominguez performed experiments to check the reproducibility of carbon growth conditions, Pd removal product characterization and tested the mechanical behavior of all samples.

Conflicts of Interest: The authors declare no conflict of interest.

\section{References}

1. Dai, K.; Liang, C.; Dai, J.; Lu, L.; Zhu, G.; Liu, Z.; Liu, Q.; Zhang, Y. High-yield synthesis of carbon nanotube-porous nickel oxide nanosheet hybrid and its electrochemical capacitance performance. Mater. Chem. Phys. 2014, 143, 1344-1351. [CrossRef]

2. Moon, J.; An, K.; Lee, Y.; Park, Y.; Bae, D.; Park, G. High-yield purification process of singlewalled carbon nanotubes. J. Phys. Chem. B 2001, 105, 5677-5681. [CrossRef]

3. Park, Y.; Choi, Y.; Kim, K.; Chung, D.; Bae, D.; An, K.; Lim, S.; Zhu, X.; Lee, Y. High yield purification of multiwalled carbon nanotubes by selective oxidation during thermal annealing. Carbon 2001, 39, 655-661. [CrossRef]

4. Wang, H.; Koleilat, G.I.; Liu, P.; Jimenez-Oses, G.; Lai, Y.; Vosgueritchian, M.; Fang, Y.; Park, S.; Houk, K.N.; Bao, Z. High-Yield Sorting of Small-Diameter Carbon Nanotubes for Solar Cells and Transistors. ACS Nano 2014, 8, 2609-2617. [CrossRef] [PubMed]

5. Zhang, G.; Mann, D.; Zhang, L.; Javey, A.; Li, Y.; Yenilmez, E.; Wang, Q.; McVittie, J.; Nishi, Y.; Gibbons, J.; et al. Ultra-high-yield growth of vertical single-walled carbon nanotubes: Hidden roles of hydrogen and oxygen. Proc. Natl. Acad. Sci. USA 2005, 102, 16141-16145. [CrossRef] [PubMed]

6. Hernandez, Y.; Nicolosi, V.; Lotya, M.; Blighe, F.M.; Sun, Z.; De, S.; McGovern, I.T.; Holland, B.; Byrne, M.; Gun'ko, Y.K.; et al. High-yield production of graphene by liquid-phase exfoliation of graphite. Nat. Nanotechnol. 2008, 3, 563-568. [CrossRef] [PubMed]

7. Joung, D.; Chunder, A.; Zhai, L.; Khondaker, S.I. High yield fabrication of chemically reduced graphene oxide field effect transistors by dielectrophoresis. Nanotechnology 2010, 21. [CrossRef] [PubMed]

8. Qian, W.; Hao, R.; Hou, Y.; Tian, Y.; Shen, C.; Gao, H.; Liang, X. Solvothermal-Assisted Exfoliation Process to Produce Graphene with High Yield and High Quality. Nano Res. 2009, 2, 706-712. [CrossRef]

9. Wang, J.; Manga, K.K.; Bao, Q.; Loh, K.P. High-Yield Synthesis of Few-Layer Graphene Flakes through Electrochemical Expansion of Graphite in Propylene Carbonate Electrolyte. J. Am. Chem. Soc. 2011, 133, 8888-8891. [CrossRef] [PubMed]

10. Knite, M.; Teteris, V.; Kiploka, A.; Kaupuzs, J. Polyisoprene-carbon black nanocomposites as tensile strain and pressure sensor materials. Sens. Actuators A Phys. 2004, 110, 142-149. [CrossRef]

11. Karimov, K.S.; Saleem, M.; Karieva, Z.M.; Khan, A.; Qasuria, T.A.; Mateen, A. A carbon nanotube-based pressure sensor. Phys. Scr. 2011, 83. [CrossRef]

12. Poveda, R.L.; Achar, S.; Gupta, N. Viscoelastic properties of carbon nanofiber reinforced multiscale syntactic foam. Compos. Part B Eng. 2014, 58, 208-216. [CrossRef]

13. Tibbetts, G.G.; Lake, M.L.; Strong, K.L.; Rice, B.P. A review of the fabrication and properties of vapor-grown carbon nanofiber/polymer composites. Compos. Sci. Technol. 2007, 67, 1709-1718. [CrossRef] 
14. Luhrs, C.; Daskam, C.; Jonathan, E.P.G. Fabrication of a Low Density Carbon Fiber Foam and Its Characterization as a Strain Gauge. Materials 2014, 7, 3699-3714. [CrossRef]

15. Atwater, M.A.; Mousavi, A.K.; Leseman, Z.C.; Phillips, J. Direct synthesis and characterization of a nonwoven structure comprised of carbon nanofibers. Carbon 2013, 57, 363-370. [CrossRef]

16. Chawla, S.; Naraghi, M.; Davoudi, A. Effect of twist and porosity on the electrical conductivity of carbon nanofiber yarns. Nanotechnology 2013, 24. [CrossRef] [PubMed]

17. Ebbesen, T.; Lezec, H.; Hiura, H.; Bennett, J.; Ghaemi, H.; Thio, T. Electrical conductivity of individual carbon nanotubes. Nature 1996, 382, 54-56. [CrossRef]

18. Inagaki, M.; Qiu, J.; Guo, Q. Carbon foam: Preparation and application. Carbon 2015, 87, 128-152. [CrossRef]

19. Silverman, E. Multifunctional carbon foam development for spacecraft applications. SAMPE J. 2005, 41, 19-23.

20. Gallego, N.; Klett, J. Carbon foams for thermal management. Carbon 2003, 41, 1461-1466. [CrossRef]

21. Rogers, D.; Plucinski, J.; Stansberry, P.; Stiller, A.; Zondlo, J. Low-Cost Carbon Foams for Thermal Protection and Reinforcement Applications; Society for the Advancement of Material and Process Engineering: Lonh Beach, CA, USA, 2000.

22. Zhang, Q.; Zhou, X.; Yang, H. Carbon foam materials prepared from polyacrylonitrile and their application in electrochemical capacitors. Acta Polym. Sin. 2003, 1, 749-753.

23. Chen, C.; Kennel, E.; Stiller, A.; Stansberry, P.; Zondlo, J. Carbon foam derived from various precursors. Carbon 2006, 44, 1535-1543. [CrossRef]

24. Yang, X.; He, P.; Xia, Y. Preparation of mesocellular carbon foam and its application for lithium/oxygen battery. Electrochem. Commun. 2009, 11, 1127-1130. [CrossRef]

25. Glenk, F.; Schirmer, M.; Guetlein, S.; Etzold, B. Synthesis of microporous Carbon Foams for Catalytic Applications. Chem. Ing. Tech. 2010, 82, 897-903.

26. Phillips, J.; Shiina, T.; Nemer, M.; Lester, K. Graphitic structures by design. Langmuir 2006, 22, 9694-9703. [CrossRef] [PubMed]

27. Phillips, J.; Leseman, Z.C.; Cordaro, J.; Luhrs, C. Novel Graphitic Structures by Design. In Proceedings of the ASME 2007 International Mechanical Engineering Congress and Exposition, Seattle, WA, USA, 11-15 November 2007.

28. Wu, N.; Phillips, J. Reaction-Enhanced Sintering of Platinum Thin-Films during Ethylene Oxidation. J. Appl. Phys. 1986, 59, 769-779. [CrossRef]

29. Wu, N.; Phillips, J. Catalytic Etching of Platinum during Ethylene Oxidation. J. Phys. Chem. 1985, 89, 591-600. [CrossRef]

30. Baker, R.T.K.; Barber, M.A.; Waite, R.J.; Harris, P.S.; Feates, F.S. Nucleation and Growth of Carbon Deposits from Nickel Catalyzed Decomposition of Acetylene. J. Catal. 1972, 26, 51-62. [CrossRef]

31. Gavillet, J.; Loiseau, A.; Journet, C.; Willaime, F.; Ducastelle, F.; Charlier, J. Root-growth mechanism for single-wall carbon nanotubes. Phys. Rev. Lett. 2001, 87. [CrossRef] [PubMed]

32. Gavillet, J.; Loiseau, A.; Ducastelle, F.; Thair, S.; Bernier, P.; Stephan, O.; Thibault, J.; Charlier, J. Microscopic mechanisms for the catalyst assisted growth of single-wall carbon nanotubes. Carbon 2002, 40, 1649-1663. [CrossRef]

33. Saito, Y.; Okuda, M.; Fujimoto, N.; Yoshikawa, T.; Tomita, M.; Hayashi, T. Single-Wall Carbon Nanotubes Growing Radially from Ni Fine Particles Formed by Arc Evaporation. Jpn. J. Appl. Phys. Part 2 Lett. Express Lett. 1994, 33, L526-L529. [CrossRef]

34. Frenklach, M. Reaction mechanism of soot formation in flames. Phys. Chem. Chem. Phys. 2002, 4, $2028-2037$. [CrossRef]

35. Atwater, M.A.; Phillips, J.; Doorn, S.K.; Luhrs, C.C.; Fernandez, Y.; Menendez, J.A.; Leseman, Z.C. The production of carbon nanofibers and thin films on palladium catalysts from ethylene-oxygen mixtures. Carbon 2009, 47, 2269-2280. [CrossRef]

36. Atwater, M.A.; Phillips, J.; Leseman, Z.C. The effect of powder sintering on the palladium-catalyzed formation of carbon nanofibers from ethylene-oxygen mixtures. Carbon 2010, 48, 1932-1938. [CrossRef]

37. Smith, P.; Cashman, J. ANSYS-Computational Fluid Dynamics (CFD) Software; Ansys, Inc.: Cecil Township, PA, USA, 2015.

38. Sarioğlan, Ş. Recovery of palladium from spent activated carbon-supported palladium catalysts. Platin. Met. Rev. 2013, 57, 289-296. 
39. Levenspiel, O. Chemical Reaction Engineering; Wiley India: New Delhi, India, 2007.

40. Fogler, H.S. Elements of Chemical Reaction Engineering; Prentice Hall PTR: Upper Saddle River, NJ, USA, 2006.

41. Baker, R.T.K.; Yates, D.J.C.; Dumesic, J.A. Filamentous Carbon Formation over Iron Surfaces. ACS Symp. Ser. 1982, 202, 1-21.

42. Walker, P.L.; Thrower, P.A. Chemistry and Physics of Carbon; Marcel Dekker: New York, NY, USA, 1978.

43. Luhrs, C.C.; Garcia, D.; Tehrani, M.; Al-Haik, M.; Taha, M.R.; Phillips, J. Generation of carbon nanofilaments on carbon fibers at $550^{\circ} \mathrm{C}$. Carbon 2009, 47, 3071-3078. [CrossRef]

44. Forsythe, W.E. Smithsonian Physical Tables, 9th Revised ed.; Knovel; Table 282. Density of Various Solids; Knovel: Norwich, NY, USA, 2003.

45. Wu, N.; Phillips, J. Carbon Deposition on Platinum during Ethylene Oxidation. J. Catal. 1988, 113, $383-397$. [CrossRef]

46. Atwater, M.A.; Phillips, J.; Leseman, Z.C. Formation of Carbon Nanofibers and Thin Films Catalyzed by Palladium in Ethylene-Hydrogen Mixtures. J. Phys. Chem. C 2010, 114, 5804-5810. [CrossRef]

47. Rasband, W.S. Image J Homepapge. National Institutes of Health: Bethesda, MD, USA. Available online: http:/ /imagej.nih.gov/ij/ (accessed on 2 November 2015).

(C) 2016 by the authors; licensee MDPI, Basel, Switzerland. This article is an open access article distributed under the terms and conditions of the Creative Commons by Attribution (CC-BY) license (http:/ / creativecommons.org/licenses/by/4.0/). 